\title{
UMA CONTRIBUIÇÃO TEÓRICA DA UTILIZAÇÃO DA ABORDAGEM CTS NO ENSINO DE CIÊNCIAS
}

\section{A THEORETICAL CONTRIBUTION OF THE USEOF THE STS APPROACH IN SCIENCE TEACHING}

Fábio Lustosa Souza ${ }^{1}$

\section{RESUMO}

A utilização da abordagem CTS no ensino de Ciências tem contribuído positivamente para a formação cidadã dos alunos, já que possibilita um melhor entendimento das variações da dinâmica social provocadas pelos avanços científico-tecnológicos. Este artigo pretende oferecer, e, ao mesmo tempo, despertar nos professores formadores do curso de Licenciatura em Química do Instituto Federal de Educação do Maranhão (IFMA) a possibilidade de apropriação de uma abordagem de ensino diferenciada, e com isto contribuir para uma reflexão de sua prática docente, possibilitando a formação de futuros professores com uma visão mais interdisciplinar e contextualizada desta área do conhecimento científico.

Palavras-chave: CTS, Formadores de Professores em Química, Ensino de Química.

\begin{abstract}
The use of STS approach in science teaching has contributed positively to the civic education of the students, because it allows a better understanding of the variations of the social dynamics caused by scientific and technological advances. This article intends to offer, and at the sametime, to awaken in theteacher educators of licentiateship in Chemistry from the Federal Institute of Education of Maranhão (IFMA), the possibility of appropriation of a differentiated instructional approach, and and thus contribute to a reflection of their teaching practice, allowing the training of future teachers with a more interdisciplinary and contextualized vision of this area of scientific knowledge.
\end{abstract}

Keywords: STS, Teacher's Educators in Chemistry, Chemistry Teaching.

\footnotetext{
${ }^{1}$ Doutorando em Ensino de Ciências e Matemática - UFMT/REAMEC
} 


\title{
CONSIDERAÇÕES PRELIMINARES
}

\begin{abstract}
$\mathrm{Na}$ vida, aprendemos quando resolvemos problemas, quando solucionamos desafios. Problemas e desafios exigem o emprego de conhecimentos apropriados anteriormente, solicitando, ao mesmo tempo, diferentes combinações e relações entre esses saberes, levando a reconstruí-los.
\end{abstract}

Roque Moraes

Diversas pesquisas (SANTOS, 2000; AULER 1998, 2003) revelam que o ensino balizado no enfoque CTS contribui com a promoção da educação científica e tecnológica dos cidadãos, de modo a lhes possibilitar construir conhecimentos, habilidades e valores necessários para tomar decisões responsáveis sobre questões de Ciência e Tecnologia na Sociedade e atuar na solução de tais questões.

Nesse sentido, o ensino apoiado nesse enfoque tem como um dos princípios a contextualização e a interdisciplinaridade. As atitudes e os valores humanísticos para atuar em questões sociais referentes à ciência e à tecnologia são desenvolvidos a partir da contextualização dos conteúdos, o que contribui na formação para o exercício da cidadania (SANTOS 2007b).

Para Auler (2003), não é possível reduzir o enfoque CTS a uma inovação didático/metodológica, uma vez que o mesmo deve estar vinculado a um profundo repensar do currículo, concebido a partir de problemas reais, contemporâneos, com abordagens interdisciplinares, o que significa dizer que os estudos CTS não são restritos ao campo das chamadas Ciências Naturais.

Todavia, o repensar do currículo nessa dimensão passa, necessariamente, pelos professores que o materializam, o que implica considerar que aquele deve ser concebido, vivenciado, compreendido e incorporado por esses atores sociais, para que dêem conta de um ensino que vincule teoria-prática, e, sobretudo, que abordem o conteúdo escolar de forma relacional e crítica.

Contudo, a formação tradicionalista dos docentes não tem permitido um ensino em que se relacionem aspectos teóricos e práticos com a interação entre ciência, tecnologia e sociedade, tornando as aulas dinâmicas com um tratamento de conteúdos que realmente faça sentido para os estudantes e tenha implicações sociais. É necessário, portanto, dar um novo rumo a esse processo formativo docente propiciando aos professores formadores a 
apropriação de conhecimentos advindos de formas metodológicas diferenciadas de ensino de Ciências, a exemplo da abordagem CTS, e que favoreçam uma prática alinhada às necessidades educacionais e sociais que se colocam no contexto atual.

Portanto, o que se pretende neste artigo é abordar como a metodologia de ensino CTS pode levar à reflexão os professores formadores da Licenciatura em Química do IFMA, uma vez que irá lhes possibilitar a apropriação de conceitos e fundamentos epistemológicos desta abordagem que ora se utiliza no ensino de Ciências, e com isto propiciar a construção de uma prática docente reflexiva, mais interdisciplinar e contextualizada.

\title{
REFLEXÕES SOBRE A ABORDAGEM CTS NO ENSINO DE CIÊNCIAS
}

\begin{abstract}
Está cada vez mais evidente que a exploração desenfreada da natureza e os avanços científicos e tecnológicos obtidos não beneficiaram a todos. Enquanto poucos ampliaram potencialmente seus domínios, camuflados no discurso sobre a neutralidade da C\&T e sobre a necessidade do progresso para beneficiar as maiorias, muitos acabaram com os seus domínios reduzidos e outros continuam marginalizados, na miséria material e cognitiva.
\end{abstract}

José André Peres Angotti e Milton Antonio Auth

Discute-se muito sobre a influência das reflexões acerca da relação CiênciaTecnologia-Sociedade (CTS) no ensino de Ciências, mas o que se pode afirmar é que sua origem data da década de setenta, em decorrência das consequências geradas pelo impacto da ciência e da tecnologia na sociedade moderna, e da mudança de visão sobre a natureza da ciência e do seu papel na sociedade, como nos afirmam Santos e Schnetzler (2000).

Auler, tratando especificamente no ensino de Ciências, destaca que o enfoque educacional CTS objetiva:

Promover os interesses dos estudantes em relacionar a ciência com as aplicações
tecnológicas e os fenômenos da vida cotidiana e abordar os estudos daqueles fatos e
aplicações científicas que tenham maior relevância social; abordar as implicações
sociais e éticas relacionadas ao uso da tecnologia e adquirir uma compreensão da
natureza da ciência e do trabalho científico (AULER, 1998, p.2).

É possível inferir, a partir deste entendimento, que dentre os objetivos a que se destina o ensino CTS está o de desenvolver a capacidade de tomada de decisão dos estudantes, bem como a compreensão dos mesmos acerca da natureza da ciência e do papel que esta desempenha na sociedade. 
Tendo em vista o alcance desses objetivos, o ensino de ciências na concepção CTS privilegia abordagens de ensino menos internalistas dando conta dos mais diversos tipos de acontecimentos da esfera social. Como bem acentua Teixeira (2003a, p.182), "o movimento CTS procura colocar o ensino de ciências numa perspectiva diferenciada, abandonando posturas arcaicas que afastam o ensino dos problemas sociais".

Neste tocante, Santos e Schnetzler (2000) ressaltam que enquanto o ensino clássico se caracteriza pela organização curricular centrada no conteúdo específico das Ciências, o ensino CTS se caracteriza por uma organização conceitual centrada em temas sociais. Neste tocante, Linsingen (2007) nos afirma que os currículos escolares, ao serem organizados sob a forma de temas sociais, devem conter estratégias de ensino centradas na participação efetiva dos alunos. Tais temas são explorados com caráter multidisciplinar, e os conceitos são abordados em uma perspectiva relacional, evidenciando as diferentes dimensões do conhecimento estudado.

O que se percebe é que a inserção de propostas pedagógicas centradas nos pressupostos do movimento CTS ganha cada vez mais interesse e destaque no ensino de Ciências no Brasil. Por outro lado, ressaltamos que pesquisas recentes mostram que, para implementar reconfigurações curriculares com uma perspectiva CTS, é necessário fornecer parâmetros e orientações com elementos mais bem delineados, além de estratégias para sua inserção, que sejam capazes de dotar o ensino de uma compreensão crítica e reflexiva sobre o contexto científico-tecnológico, e suas relações com a sociedade.

Essa é uma perspectiva que se aponta nas orientações dos Parâmetros Curriculares Nacionais (PCN), no que tange especificamente às relações entre ciência, tecnologia e sociedade, documento no qual se ressalta que:

As questões éticas, valores e atitudes compreendidas nessas relações são conteúdos fundamentais a investigar nos temas que se desenvolvem em sala de aula. A origem, o destino social dos recursos tecnológicos, o uso diferenciado nas diferentes camadas da população, as consequiências para a saúde pessoal e ambiental e as vantagens sociais do emprego em determinadas tecnologias também são conteúdos de "Tecnologia e Sociedade" (BRASIL, 1998, p. 48).

Tal entendimento implica o desafio do ensinar/aprender Ciências, referenciados pelo debate crítico das questões sociais, morais e éticas derivadas do desenvolvimento científicotecnológico.

Corroborando com este entendimento, Vieira e Martins (2009) nos afirmam que é por intermédio desta abordagem metodológica que o aluno conseguirá fazer relações entre os conhecimentos científicos além da sala de aula, buscando compreender a dimensão social da 
ciência e da tecnologia, tanto do ponto de vista de seus antecedentes sociais como de suas consequiências sociais e ambientais.

Lópes e Cerezo (1996), que são pesquisadores espanhóis da área de ensino de Ciências, corroboram este entendimento ao afirmarem que trabalhar os conteúdos científicos, segundo a abordagem CTS, significa ensinar os conteúdos no contexto autêntico do seu meio tecnológico e social, no qual os estudantes integram o conhecimento científico com a tecnologia e o mundo social de suas experiências do dia-a-dia.

No Brasil, diversos pesquisadores, a exemplo de Santos e Mortimer (2003, 2009), trabalham com a abordagem de temas sócio-científicos no ensino de Ciências, com objetivo de desenvolver atitudes e valores em uma perspectiva humanística. Ademais, as contribuições de outros pesquisadores, tais como Auler (2003), Delizoicov (2004), Auler \& Delizoicov (2001) e Coelho \& Marques (2007), Santos (2008) e Santos \& Mortimer (2002), destacam, ainda, a necessidade de incorporar ao currículo de Ciências as discussões de valores e reflexões críticas que possibilitem desvelar a condição humana dos alunos, permitindo-lhes refletirem sobre sua situação no mundo frente aos desafios postos pela ciência e tecnologia.

Como Auler \& Bazzo (2001) nos questionam:

\begin{abstract}
Não estaria o imaginário de boa parte dos brasileiros, entre os quais professores de Ciências, aspirando a um mundo, a um modelo de sociedade, exemplificado pelos chamados países capitalistas centrais? O movimento CTS surgiu exatamente nesses países porque uma parte da população começou a questionar esse modelo, essa sociedade. Uma mudança de percepção em relação ao papel da C\&T na vida das pessoas, um dos elementos centrais e motivador desse movimento, já aconteceu em nosso contexto?
\end{abstract}

Já Libâneo (2005), por seu turno, encaminha-se nessa direção ao afirmar que a educação científica deve promover nos estudantes o desenvolvimento de capacidades cognitivas e sociais que contribuam para a apropriação crítica dos benefícios da ciência e da tecnologia em favor do trabalho, da vida cotidiana e do crescimento pessoal.

No âmbito internacional, é possível também identificar que o movimento CTS no ensino de Ciências avança a partir de contribuições de diversos pesquisadores, tais como Membiela (2003), Aikenhead (1994), Iglesia (1995), Holman (1988), Rubba \& Wiesenmayer (1988), Aikenhead (1994), Zimmermann \& Mamede (2005), Valdés et al (2002), AcevedoDíaz \& Acevedo-Romero (2002), Vilches apud Membiela (2001), Linsingen (2007), Cachapuz (2008), dentre outros. 
Contudo, é importante reconhecer que os avanços no campo do ensino das Ciências, com base no movimento CTS, trazem em si a necessidade urgente de que seja redimensionado o ser e o fazer a docência, o que implica, em primeiro plano, a revisão das práticas que predominam no processo de formação desse professor.

No que se refere à formação de professores, Carvalho \& Pérez (2006, p.14) mencionam as lacunas na formação inicial, além de evidenciar que os professores que já atuam na área de Ciências, não só carecem de formação continuada, como também precisam se conscientizar de suas próprias insuficiências. Urge, portanto, a necessidade de que, por parte dos educadores, seja lançado um novo olhar sobre a sua própria prática de ensino e sobre o papel político social da ciência para a vida concreta dos cidadãos.

E, por fim, calha frisar o que Freire (1996) nos deixou de legado ao afirmar que "somos seres inconclusos, estamos em permanente processo de transformação, o que traz a necessidade de desestabilizarmos as certezas, rever os conceitos, buscando novas formas de conhecimento e nos disponibilizando ao novo com todos os riscos e possibilidades que ele nos gera”.

\title{
A ABORDAGEM CTS VERSUS OS FORMADORES DE PROFESSORES DE QUÍMICA
}

\begin{abstract}
O ensino prático reflexivo deve cultivar atividades que conectem o conhecimento e a reflexão-na-ação dos profissionais competentes com as teorias e técnicas ensinadas como conhecimento profissional nas disciplinas acadêmicas (SCHÖN, 2000, p.228).
\end{abstract}

No Brasil, ainda são escassos os trabalhos existentes na literatura, que tratam do planejamento e aplicação de atividades pedagógicas com orientação CTS na formação de professores de Ciências. Nos últimos anos, pesquisadores desta área têm envidado esforços na tentativa de apontar novos rumos que contribuam para uma efetiva renovação na formação destes profissionais, a exemplo das pesquisas desenvolvidas por Maldaner (2000), Carvalho (2007), Rosa e Schnetzler (2003).

Essa busca por novos rumos decorre do entendimento de que as mudanças no ensino de Ciências com implicações pra a vida dos alunos e da sociedade exigem ações no âmbito da formação e do desenvolvimento profissional, pessoal e social dos professores. Em síntese, tais 
ações deverão constituir-se meios privilegiados para inovar o ensino de Ciências, condição fundamental para promover aprendizagens significativas e relevantes para a vida dos seus destinatários nas sociedades contemporâneas.

Nóvoa (1992), pesquisador português que se destaca na área de formação de professores, nos ensina que na perspectiva CTS há a necessidade de formação de cidadãos críticos que respondam às questões do cotidiano, o que não será conseguido sem uma adequada formação profissional. Segundo o mesmo autor:

É preciso instrumentalizar o futuro professor para planejar, desenvolver e avaliar atividades pertinentes à abordagem CTS, considerando ainda que não há ensino de qualidade, nem reforma educativa, nem inovação pedagógica sem uma adequada formação de professores (pág. 9).

Segundo o mesmo autor, a reflexão docente é fator preponderante para a construção de um trabalho docente. Eis, abaixo, o que o mesmo nos afirma:

A formação não se constrói por acumulação (de cursos, de conhecimentos ou de técnicas), mas sim através de um trabalho de reflexividade crítica sobre as práticas e de (re) construção permanente de uma identidade profissional (NÓVOA, pág.25).

Todavia, devemos ressaltar que diversas pesquisas realizadas com professores de Ciências de outros países revelam questões-problemas de naturezas diversas, que interferem na formação destes profissionais.

Como exemplo do que acima se apontou, citamos Vilches e Gil apud Membiela (2001a), que apontam que a estrutura organizacional escolar e a sobrevalorização do conhecimento específico são alguns dos fatores que interferem na adoção de uma abordagem CTS no ensino de Ciências.

Outra constatação da prática docente atual no ensino de Ciências é o que Vieira e Martins (2004) nos afirmam: "alguns professores de Ciências persistem em adotar o modelo de transmissão e recepção nos processos de ensino e aprendizagem, com ausência das abordagens CTS”.

Outras investigações que vão nesta linha de pensamento denunciam que os professores possuem concepções inadequadas de ciência, tecnologia e sociedade (ACEVEDO-DÍAZ e ACEVEDO-ROMERO, 2002; VALDÉS et al., 2002; MARTINS, 2003). Isto reforça a necessidade de que se possa estabelecer uma discussão mais profícua sobre as questões relativas aos avanços tecnológicos e científicos bem como suas implicações na sociedade. 
A título de exemplificação, citamos Amorim (1997), que, em uma pesquisa realizada com professores de Biologia do ensino médio, identifica a predominância da concepção de que a ciência é algo externo à sociedade, e de que a tecnologia se reduz à aplicação do saber científico nessa sociedade, não considerando que o trabalho científico e os aparatos tecnológicos encontram-se sujeitos aos determinantes sociais. Alerta ainda o autor que o discurso que predomina no meio educacional é de que o desenvolvimento científicotecnológico é o grande desencadeador de benfeitorias para a humanidade sem distinção de nações e classes sociais, sem dar ênfase às questões relativas à dominação e à dependência político-econômica.

Por outro lado, estudos desenvolvidos por Vieira e Martins (2004), Zimmermann e Mamede (2005) ressaltam que se houverem investimentos na formação docente para uma abordagem CTS no ensino de Ciências é possível que os futuros professores desenvolvam projetos de ensino de orientação CTS. Nesta mesma direção, encontramos em Acevedo-Díaz (2002) e Acevedo-Romero (2002) entendimentos que destacam que a formação docente, quando devidamente orientada, pode contribuir para a (re) elaboração de concepções mais adequadas de ciência, tecnologia e sociedade.

No que se refere aos saberes docentes e ao desenvolvimento profissional, podemos identificar elementos que compõem esse conjunto de saberes e habilidades consoantes ao “educador CTS”, ou seja, àquele profissional que pretende desenvolver uma ação pedagógica compatível com as orientações do enfoque CTS para o ensino de ciências (TARDIF, 2002).

Relativamente ao ensino de física, como exemplo prático, utilizando a abordagem CTS, o referido autor acima nos diz que:

\section{O entendimento sobre o conjunto de saberes que os professores mobilizam deve ser investigado, considerando-se a posição estratégica que esses profissionais ocupam dentro das sociedades contemporâneas e dentro da perspectiva CTS para o ensino de Física (TARDIF, 2002).}

A esses saberes, o autor denominou de "saberes docentes", e os definiu como sendo "um saber plural, formado pelo amálgama, mais ou menos coerente, de saberes oriundos da formação profissional e de saberes disciplinares, curriculares e experienciais" (TARDIF, 2002, p.36).

Para o mesmo autor, a prática docente integra saberes distintos e mantém diferentes relações com eles, encontra-se apoiada em fundamentos existenciais, sociais e pragmáticos adquiridos ao longo da vida, os quais constituem os saberes docentes (ibidem). 
Quanto à formação de professores de Química, fazemos uma referência às pesquisas acadêmicas de Mortimer e Santos (2002), que nos assinalam que "a existência de um enfoque CTS nas estruturas curriculares das faculdades formadoras destes profissionais torna-se importante e urgente, uma vez que tal abordagem diferencia e promove qualidade ao processo ensino-aprendizagem". Portanto, tem que figurar na formação inicial e continuada do professor, assim como na formação do aluno, desde o nível mais elementar (ensino fundamental) até o seu ingresso no ensino superior, a fim de que tenha uma capacitação de qualidade e alcance seu espaço no processo de inserção social.

Nessa mesma direção, Auler (2003) nos coloca que:

O enfoque CTS não pode ser interpretado como um conteúdo curricular, e sim, como uma concepção e maneira de ensinar. Com isso, o professor precisa saber implementar situações de ensino que articule teoria e prática no processo de aprendizagem de forma a priorizar a prática do questionamento reflexivo crítico por meio de situações problemas do cotidiano e de relevância social.

A perspectiva de uma prática movida pela reflexão crítica pressupõe que os (as) professores (as) dominem com profundidade os conteúdos que ensinam e desenvolvam um tratamento em que estes sejam compreendidos em interface com as dimensões culturais, políticas e sociais do contexto em que são produzidos e para onde se voltam. Ademais, implica a capacidade que estes profissionais possuam para refletir acerca da problemática do seu cotidiano e agir sobre ela, sem deter-se apenas na resolução de problemas imediatos, ampliando os horizontes da reflexão de modo a abranger a função da escola e da educação no âmbito da sociedade.

Portanto, a capacidade de refletir além de propiciar a leitura crítica dos conteúdos de ensino e da experiência vivenciada, conduz o profissional professor a um processo de criação, que transcende a mera aplicação de esquemas de ação resultantes de saberes acumulados. É necessário, nesse sentido, superar as práticas marcadas pelo individualismo, a partir do entendimento de que este é um desafio coletivo em que professores (as) se apóiam mutuamente ao partilharem conjuntamente problemas e práticas, produzindo saberes teóricopráticos que vão ao encontro das exigências e das necessidades postas ao exercício profissional.

Schön (1992), ao propor uma nova concepção de formação de professores (marcada por incertezas, conflitos, singularidades que transcendem as categorias teoria e prática), afirma-nos que é necessária a superação da "racionalidade técnica" que caracteriza os cursos 
de formação de professores - o que ele define como "epistemologia da prática" - e ao propor a reflexão como elemento central na preparação dos profissionais para as demandas da prática.

Pimenta (2002) nos diz que a proposta de Schön trouxe contribuições ao campo da formação de professores, dentre as quais, destacamos: i) a consideração do professor como sujeito participante e não apenas executor de reformas emanadas de instâncias externas; ii) a importância da formação contínua como possibilidade de atendimento às demandas inerentes à prática; e iii) a necessidade de refletir sobre o currículo adequado à formação do professor reflexivo e sobre as condições do exercício da reflexão nas escolas.

Contreras (2002), ao se contrapor às ideias de Schön, enfatiza a necessidade de os professores desenvolverem sua autonomia, ao assumirem uma postura reflexiva e crítica, concebendo o ensino como prática social, através da interrogação sobre os resultados e a pertinência de seu trabalho e por meio da pesquisa, notadamente quando permite articular conhecimento e ação, superar a separação entre quem produz conhecimento e quem atua como docente, criar condições para transformar a prática do professor e questionar a visão instrumental da prática.

Ainda, segundo o mesmo autor:

Conceber o trabalho dos professores como trabalho intelectual quer dizer, portanto, desenvolver um conhecimento sobre o ensino que reconheça e questione sua natureza socialmente construída e o modo pelo qual se relaciona com a ordem social, bem como analisar as possibilidades transformadoras implícitas nos contexto social das aulas e do ensino. (CONTRERAS, 2002, p.157-158).

Para Zeichner (1993), a reflexão do professor não deve ser somente sobre sua prática, para que ele não recaia numa espécie de isolamento, mas deve se dar de modo coletivo.

Isto reforça a necessidade de que as disciplinas que integram o currículo dos cursos de licenciatura em Química possam dialogar entre si, na busca pela interação entre os conhecimentos científicos.

Outro pesquisador nos destaca que "a reflexão sobre a prática permitiria aos professores avançar num processo de transformação dessa prática pedagógica, já que este processo de reflexão permite intervenções e mudanças, haja vista que um bom professor não se faz apenas com teorias, mas especialmente com a prática e o estímulo a uma ação-reflexão e a uma busca constante de um saber mais e de um fazer melhor" (GHEDIN, 2002, p.132). 
Ainda, nesta senda:

\begin{abstract}
Pensar a reflexão como caminho exige-nos um ato de vontade e um ato de coragem gerador e impulsionador de mudança. Todos os limites impostos à reflexão não são mais que portas abertas em direções que ainda não havíamos percebido. Tal apologia da reflexão tem por suporte a mais firme razão de que sem ela não podemos ter acesso ao ser da humanidade. Somente desta maneira poderemos possibilitar a construção da cidadania responsável (GHEDIN, 2002, pág. 148).
\end{abstract}

Desta forma, observamos que a reflexão da prática docente passa a ser tomada como um elemento central e imprescindível no processo formativo de futuros professores, possibilitando-lhes uma integração entre a teoria e a prática, a construção de conhecimentos a partir das suas experiências, o aprimoramento de sua ação pedagógica e, em especial, a construção de sua autonomia pessoal e profissional.

\title{
CONSIDERAÇÕES FINAIS
}

A prática de ensino conhecida mundialmente como abordagem CTS preocupa-se com a realização de atividades de caráter interdisciplinar, que buscam a contextualização dos conteúdos científicos, através da consideração de aspectos sociais relativos às aplicações da ciência e da tecnologia.

Mortimer \& Santos (2002) nos ensinam que a existência de um enfoque CTS nas estruturas curriculares das instituições formadoras dos professores de Química se faz importante, uma vez que a abordagem CTS diferencia e melhora o processo de ensino e aprendizagem, e cada vez mais deve estar presente na formação continuada do professor, para que este obtenha uma capacitação de qualidade e alcance seu espaço durante o processo de inserção social.

Nesse sentido, concordamos com o que diz Contreras (2002)que não restam dúvidas de que o professor deve refletir sobre a sua prática pedagógica, a fim de construir criticamente um novo trabalho intelectual a serviço da transformação social, na busca de sua autonomia.

Porém, há grandes desafios a serem superados por parte dos professores formadores nos cursos de licenciatura em Química, tais como: i) a falta de preparo para lidar com as questões cotidianas da sala de aula; ii) os modelos de formação que se aproximam das 
características do curso de bacharelado; iii) a concepção do professor como técnico; e iv) o distanciamento evidente entre escola e universidade, pesquisa e ensino, teoria e prática. Superados estes obstáculos que hoje caracterizam um modelo pedagógico simplista de transmissão-recepção, que impede o entendimento da complexidade que é a prática docente, é que permitiremos a construção de uma prática docente reflexiva e contextualizada (SCHNETZLER \& ARAGÃO, 2005).

\section{REFERÊNCIAS}

ACZEVEDO, J. A. (1996). Cambiando la práctica docente en la enseñanza de las ciências a través de CTS. Borrador, 13, pp. 26-30. En línea en Sala de Lecturas CTS+I de la OEI. Recuperado em 11/09, 2010, de < http://www.campusoei.org/salactsi/acevedo2.htm.

AULER, D. Alfabetização científico-tecnológica: um novo "paradigma"? Ensaio - Pesquisa em Educação em Ciências, 5 (1), 1-16, 2003. < http://www.fae.ufmg.br/ensaio/v5_n1/516.pdf TARDIFF, M. Saberes docentes e formação profissional. Petrópolis. Vozes, 2002.

CARVAlHO, Anna M. Pessoa, PERES, Gil Daniel. Formação de Professores de Ciências. 8. ed. São Paulo Cortez, 2006.

CONTRERAS, José. A autonomia de professores. São Paulo: Cortez, 2002.

FREIRE, Paulo. Pedagogia da Autonomia: saberes necessários para a pratica educativa. São Paulo: paz e terra, 1996.

GHEDIN, E. Professor reflexivo: da alienação da técnica à autonomia da crítica. In: PIMENTA, S. G.; GHERDIN, E. Professor reflexivo no Brasil: gênese e crítica de um conceito. 2. ed. São Paulo: Cortez, 2002, p. 129-150

LIBÂNEO, J. C. (2005). As teorias pedagógicas modernas revisitadas pelo debate contemporâneo na educação. In: LIBÂNEO, J. C.; SANTOS, A. (orgs). A educação na era do conhecimento em rede e transdisciplinaridade, p. 19-62. Campinas, SP: Alínea.

NÓVOA, Antonio. Formação de professores e profissão docente. In: NÓVOA, Antonio (Org). Os Professores e sua Formação. Lisboa, Publicações Dom Quixote, 1992. . Os professores e a sua formação. Lisboa: Dom Quixote, 1992. 
MALDANER, O. A. A formação inicial e continuada de professores de química: professor/pesquisador. Ijuí: Ed. Unijuí, 2003.

MORTIMER, E. F.; Santos, W. L. P. Uma análise de pressupostos teóricos da abordagem CTS (Ciência -Tecnologia -Sociedade) no contexto da educação brasileira. Disponível em: $<$ http://www2.ufpa.br/ensinofts/artigos2/wildsoneduardo.pdf $>$. Acesso em: 16 agosto de 2011.

SANTOS, W. L. P e SCHNETZLER, R. P. Educação em Química: compromisso com a cidadania. Ijuí: Editora Unijuí, 2000.

SCHON, Donald A. (1992). Formar professores como profissionais reflexivos. In: A. Nóvoa (Eds.). Os professores e a sua formação, (pp. 115-138). Lisboa: Ed. Dom Quixote

VIEIRA, R. M. \& MARTINS, I. P. (2004) Impacto de um programa de formação com uma orientação CTS/PC nas concepções e práticas de professores. In I. P. Martins; F. Paixão \& R. M. Vieira, Perspectivas Ciência-Tecnologia-Sociedade na Inovação da Educação em Ciência. (pp. 47-55) Aveiro: Universidade de Aveiro.

ZEICHNER, K. M. (1993). A Formação Reflexiva de Professores: Idéias e Práticas. Lisboa: Educa. 